Journal of Hazardous Materials

October 2018, Volume 360, Pages 452-460

http://dx.doi.org/10.1016/i.jhazmat.2018.07.101

http://archimer.ifremer.fr/doc/00452/56369/

(c) 2018 Elsevier B.V. All rights reserved.

\title{
Ingestion and contact with polyethylene microplastics does not cause acute toxicity on marine zooplankton
}

\author{
Beiras R. ${ }^{1,{ }^{*}}$, Bellas J. ${ }^{2}$, Cachot J ${ }^{3}$, Cormier B. ${ }^{4}$, Cousin Xavier ${ }^{5,6}$, Engwall M. ${ }^{4}$, Gambardella C. ${ }^{7}$, \\ Garaventa F. ${ }^{7}$, Keiter S. ${ }^{4}$, Le Bihanic F. ${ }^{3}$, López-lbáñez S. ${ }^{1}$, Piazza V. ${ }^{7}$, Rial D. ${ }^{2}$, Tato T. ${ }^{1}$, \\ Vidal-Liñán L. ${ }^{2}$
}

${ }^{1}$ ECIMAT, University of Vigo, Illa de Toralla E-36331, Vigo, Galicia, Spain

${ }^{2}$ Centro Oceanográfico de Vigo. Instituto Español de Oceanografía, Cabo Estay, E-36390, Vigo, Galicia, Spain

${ }^{3}$ Bordeaux University, EPOC, UMR CNRS 5805, Avenue des Facultés, 33400 Talence, France

${ }^{4}$ Man-Technology-Environment Research Centre, School of Science and Technology, Örebro

University, Fakultetsgatan 1, 70182 Örebro, Sweden

${ }^{5}$ IFREMER, Laboratoire Adaptation et Adaptabilités des Animaux et des Systèmes, UMR MARBEC, chemin de Maguelone, 34250 Palavas, France

${ }^{6}$ UMR GABI INRA, AgroParisTech, Université Paris-Saclay, F-78350 Jouy-en-Josas, France

${ }^{7}$ CNR-ISMAR, Via de Marini 6, 16149 Genova, Italy

*Corresponding author : R. Beiras, email address : rbeiras@uvigo.es

\begin{abstract}
:
Toxicity of polyethylene microplastics (PE-MP) of size ranges similar to their natural food to zooplanktonic organisms representative of the main taxa present in marine plankton, including rotifers, copepods, bivalves, echinoderms and fish, was evaluated. Early life stages (ELS) were prioritized as testing models in order to maximize sensitivity. Treatments included particles spiked with benzophenone-3 (BP-3), a hydrophobic organic chemical used in cosmetics with direct input in coastal areas. Despite documented ingestion of both virgin and BP-3 spiked microplastics no acute toxicity was found at loads orders of magnitude above environmentally relevant concentrations on any of the invertebrate models. In fish tests some effects, including premature or reduced hatching, were observed after $12 \mathrm{~d}$ exposure at $10 \mathrm{mg} \mathrm{L}-1$ of BP-3 spiked PE-MP. The results obtained do not support environmentally relevant risk of microplastics on marine zooplankton. Similar approaches testing more hydrophobic chemicals with higher acute toxicity are needed before these conclusions could be extended to other organic pollutants common in marine ecosystems. Therefore, the replacement of these polymers in consumer products must be carefully considered.
\end{abstract}




\section{Graphical abstract}

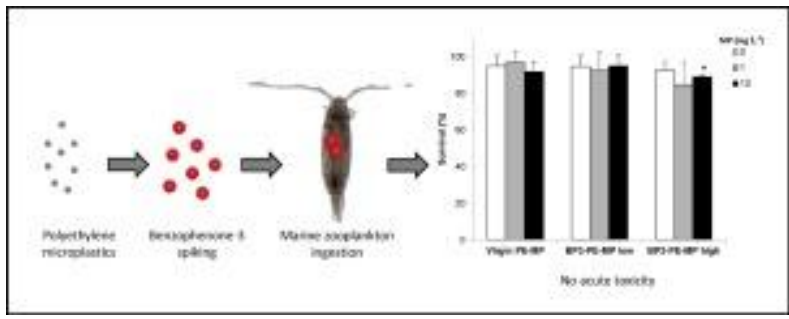

\section{Highlights}

- PE-MP are ingested by organisms representative of zooplanktonic marine taxa. Virgin or BP-3 spiked PE-MP do not cause toxic effects on marine zooplankton. BP-3 spiked PE-MP cause premature hatching of fish eggs compared with virgin PE-MP. PE-MP do not pose remarkable environmental risk on marine plankton communities.

Keywords : polyethylene, marine litter, marine zooplankton, Benzophenone-3, Embryo-larval bioassays 


\section{Introduction}

According to recent estimations, between 4.8 and 12.7 million Tons of plastic litter enter the global oceans every year [1]. Conventional plastic polymers are not biodegradable and they are supposed to persist in the environment for hundreds of years. However, plastic debris both 
floating in open ocean [2], or sunk in the bottom [3] do not show increasing temporal trends. The combination of thermo-oxidative breakage of the polymeric chains, photodegradation, and leaching of plasticizing additives make plastic objects increasingly brittle and susceptible to mechanical abrasion, especially in high energy environments such as the exposed coastline. Therefore, fragmentation of plastic objects into particles within the microns range, termed microplastics (MP), has been suggested to explain this paradox. In fact abundance of MP on surface waters has increased over the last few decades [4], although no clear temporal trends have also been reported [5]. The ingestion of MP by marine zooplanktonic organisms is well documented $[6,7]$, and it has been suggested to be a significant input of plastics into the marine trophic webs [8]. Toxicity of MP to planktonic organisms though is a debatable issue, and both reports on acute toxicity [9-11] and lack of effects [12-14] have been published, with endpoints related to motility being specially sensitive [15].

Polyethylene (PE) is the plastic polymer with the highest global production [16], and the most frequently identified in marine litter $[16,17]$. PE shows a very low glass transition temperature and plasticizers are not needed in PE objects. However it is susceptible to photo-oxidation, and UV stabilizers are added in outdoor applications. Benzophenone-3 (BP-3, CAS: 131-57-7), IUPAC name (2-hydroxy-4-methoxyphenyl)-phenylmethanone, is a common UV filter used in cosmetics such as sunscreen body creams in amounts between $5-10 \%$ of the final product, and as light stabilizer in plastics. The use in sunscreens represents a direct input in coastal waters, were maximum levels reported reached from 0.4 [18] to $3.3 \mu \mathrm{g} \mathrm{L}^{-1}$ [19]. The hydrophobicity of this chemical (log $\left.\mathrm{K}_{\mathrm{ow}}=3.79\right)$ predicts its sorption to MP.

Early life stages (ELS) of copepods, bivalves, sea-urchins and fish are extremely sensitive to chemical pollutants, with acute toxicity thresholds frequently in the order of $10-100 \mu \mathrm{g} \mathrm{L}^{-1}[20-$ 22]. For this reason, ELS are frequently used for the assessment of pollution in the marine environment, and internationally accepted standard methods are available [23]. According to 
literature, MP loads in seawater are within the $\mu \mathrm{L} \mathrm{L}^{-1}$ range, and the highest MP loads reported in the sea are around 0.08 to $0.3 \mathrm{mg} \mathrm{L}^{-1}[24,25]$. Following the precautionary principle, we have tested MP effects at densities up to $10-100 \mathrm{mg} \mathrm{L}^{-1}$, far above current environmental concentrations.

The aim of this study was to test whether the ingestion of, or direct contact with, virgin or BP3-spiked PE MP caused acute toxicity to a battery of species representative of the main systematic groups present in marine zooplankton, including rotifers, bivalve, crustacean, echinoderm and chordate ELS.

\section{Materials and methods}

\subsection{Microplastics}

Not fluorescent low-density PE microplastics (hereafter PE-MP), with 0.96 to $0.99 \mathrm{~g} / \mathrm{cm}^{3}$ density and particle sizes ranging from 1 to $500 \mu \mathrm{m}$ were purchased from Micro Powders Inc. (NY-USA), Cospheric (CA, USA), and Rotogal (Boiro, Galicia, Spain). These included CPMS-0.96 (size range 1-4 $\mu \mathrm{m}), \operatorname{MPP}-635 \mathrm{XF}(4-6 \mu \mathrm{m}), \mathrm{MPP}-635 \mathrm{G}(11-13 \mu \mathrm{m})$, Aquatex-325 (11-15 $\mu \mathrm{m})$, Aquamatte (6-8.5 $\mu \mathrm{m})$, MPP-1241 $(20-25 \mu \mathrm{m})$, and Rotogal micronized PE $(<500 \mu \mathrm{m})$, the latter sieved by 40 or $63 \mu \mathrm{m}$ prior to toxicity testing. In addition, fluorescent green (FMG-1.3, nominal size $1-5 \mu \mathrm{m}, 1.3 \mathrm{~g} / \mathrm{cm}^{3}$ density, $414 \mathrm{~nm}$ excitation/515 nm emission) and fluorescent red (FMR-1.3, nominal size 1-5 $\mu \mathrm{m}, 1.3 \mathrm{~g} / \mathrm{cm}^{3}$ density, $575 \mathrm{~nm}$ excitation/607 nm emission) PE particles purchased from Cospheric were used for documenting particle ingestion in rotifers, copepod and mussel larvae.

\subsection{Chemicals}

Potassium dichromate (VI) $\left(\mathrm{K}_{2} \mathrm{Cr}_{2} \mathrm{O}_{7}\right)$, BP-3 (purity $\geq 98 \%$,), and polyoxyethylene (20) polyethylene glycol sorbitan monolaurate $\left(\operatorname{Tween}^{\circledR 20}\right.$,) were purchased from Sigma-Aldrich (Schnelldorf, Germany). Other chemicals were of analytical grade, and included copper 
standard solution from Fischer Scientific (Portugal), toluene, 3,5-dichlorophenol (3,5-DCP,), and dimethyl sulfoxide (DMSO,) from Sigma-Aldrich (Germany). Internal standards as 2,3,4,5,6pentadeuteriobenzoic acid, 1-bromo-4-phenylbenzene, $\quad 1,2,3,4,5,6,7,8$ octadeuterionaphthalene and 1,2,3,4,5-pentachloro-6-(2,3,4,5,6-pentachlorophenyl)benzene were purchased from Sigma Aldrich, and 1,2,3,4,5,6,7,8,9,10-decadeuteriophenanthrene was purchased from CDN Isotopes. Solvent used for the extraction of BP-3 were purchased from Promochem, ethyl acetate and cyclohexane. Sartorius provided syringe filter RC4, for the filtration of microplastics. A stock solution of BP-3 was prepared by dilution in DMSO, and diluted in distilled water and in natural $0.22 \mu \mathrm{m}$-filtered sea water (FSW), 37\%o salinity. The final concentration of DMSO never exceeded the NOEC previously found for this chemical for each testing organism.

\subsection{BP-3 spiking}

For the preparation of BP-3 spiked MP (hereafter BP3-PE-MP), we aimed at two concentrations that represented, according to literature data, a concentration most likely showing effects (hereafter termed 'high' concentration), and a more environmental relevant concentration ('low' concentration)[18, 26-29]. To create the different concentrations, $25 \mathrm{~g}$ of MP particles were transferred into each of 5 separate $250 \mathrm{~mL}$ narrow-mouth Septa bottles (Thermo scientific), for a final MP concentration of $125 \mathrm{~g} \mathrm{~L}^{-1}$. BP-3 concentrations in the stock solutions (0.1\% toluene) were $20 \mu \mathrm{g} \mathrm{L}^{-1}$ for the high concentration, and $200 \mathrm{ng} \mathrm{L}^{-1}$ for the low concentration. The bottles were placed on a rotary shaker at the lowest speed $(20 \mathrm{rpm})$ for 2 days. Filtration of the samples was done using a funnel and glass microfiber filter $(1.0 \mu \mathrm{m}$, Whatman ${ }^{\circledast}$ glass microfiber filters, GE Healthcare Life Sciences). Samples were transferred on the filter, and plastic debris were rinsed with double-deionized water and dried by vacuum evaporation on a ceramic funnel. After 2 days the concentrations on the plastic were determined using an aliquot of the sample $(0.3 \mathrm{~g})$ spiked with internal standards (i.a. ,3,4,5,6- 
pentadeuteriobenzoic

acid,

1-bromo-4-phenylbenzene,

$1,2,3,4,5,6,7,8-$

octadeuterionaphthalene, 1,2,3,4,5-pentachloro-6-(2,3,4,5,6-pentachlorophenyl)benzene, and 1,2,3,4,5,6,7,8,9,10-decadeuteriophenanthrene) and concentrated with a factor of 10 .

The samples were extracted with a solvent mixture: ethyl acetate/cyclohexane (1:1). Additionally, an external calibration standard, a blank sample and a recovery sample were prepared. The extracts were measured with $\mathrm{GC} / \mathrm{MS} / \mathrm{MS}$, electron impact ionization (GC: Agilent 7890A, MS/MS: Agilent 7000 Multiple-Reaction Monitoring (MRM) mode) using a splitless injection of $2 \mu \mathrm{L}$ (column DB5-MS, $30 \mathrm{~m} \times 0.25 \mathrm{~mm} \times 0.25 \mu \mathrm{m}$ ) Identification and quantification was performed against the retention time and the external calibration using the compound specific Selected Reaction Monitoring (SRM, one quantifier and one qualifier).

\subsection{Toxicity testing}

\subsubsection{Brachionus plicatilis}

Acute test toxicity tests were performed with the rotifer Brachionus plicatilis, following standard methods $[30,31]$. Rotifers were obtained by hatching cysts purchased from MicroBioTests, Inc. (Gent, Belgium). Briefly, cysts were placed into Petri dishes $(\varnothing 6 \mathrm{~cm}$ ) containing $10 \mathrm{ml}$ of FSW at $20 \%$ salinity and incubated at $25^{\circ} \mathrm{C}$ at an illumination level of 1000 to 3000 lux. The stock was considered suitable for testing when approximately $50 \%$ of cysts have hatched in $24 \mathrm{~h}$. For the bioassay, $24 \mathrm{~h}$-hatched rotifers were transferred by Pasteur pipette into a beaker in a final concentration of $10-15$ organisms per $\mathrm{ml}$. Then, they were placed in glass vials containing $1 \mathrm{~mL}$ of reference toxicant $\left(\mathrm{K}_{2} \mathrm{Cr}_{2} \mathrm{O}_{7}\right)$, control seawater, or serial dilutions of BP-3, PE-MP and BP3-PE-MP (see Tables 1 and 2). Rotifers were placed in an orbital shaker set at $1 \mathrm{rpm}$ and incubated at $25^{\circ} \mathrm{C}$ for $48 \mathrm{~h}$. No surfactant was added. The reference toxicant $\mathrm{K}_{2} \mathrm{Cr}_{2} \mathrm{O}_{7}$ was used to check the biological quality of the stock at the following concentrations: $0,0.12,0.25,0.5-1 \mathrm{mg} \mathrm{L}^{-1}$. Endpoints recorded after $48 \mathrm{~h}$ were mortality and immobility. Dead organisms were characterized by a lack of movement, including mastax and 
foot movement, for $5 \mathrm{~s}$, and immobile organisms were considered those that do not swim nor shift their barycentre but move their appendages. Each treatment, including the control, was prepared in triplicates.

In addition, 1-4 $\mu \mathrm{m}$ polyethylene green fluorescently labelled particles were employed for evaluating MP accumulation in rotifers after $48 \mathrm{~h}$. Tests were performed as described above. Following exposure, the organisms were removed and washed with fresh FSW three times to remove MP bound to the exoskeleton: in this way, according to Nasser and Lynch [32], only ingested particles would be assessed. Organisms were fixed in $4 \%$ paraformaldhehyde solution in phosphate-buffered saline (PBS, $\mathrm{pH}$ 7.4) and observed under an Olympus BX61 epifluorescence microscope. Images were acquired, stored and displayed with a software program, using TIFF image format.

\subsubsection{Tigriopus fulvus}

Acute toxicity tests with the crustacean $T$. fulvus, a harpacticoid copepod widely distributed in the Mediterranean Sea, were performed following the UNICHIM protocol [33], based on the international standard ISO14669 [34]. T. fulvus adults were maintained in laboratory culture inside $0.5 \mathrm{~L}$ polystyrene tissue culture flasks at $20 \pm 2{ }^{\circ} \mathrm{C}$ with a $16: 8$ light/dark photoperiod. Nauplii originating from synchronised cultures (24h) were obtained from ovigerous females [35].

For the bioassay set-up, $1 \mathrm{~mL}$ of nauplii (15/20 organisms per $\mathrm{mL}$ ) were transferred by using a Pasteur pipette into small glass vials containing $1 \mathrm{~mL}$ of reference toxicant $\left(\mathrm{Cu}^{2+}\right)$, control FSW, or serial dilutions of BP3, PE-MP and BP3-PE-MP (see Tables 1 and 2). The reference toxicant $\mathrm{Cu}^{2+}$ was used to check the biological quality of the stock at the following concentrations: 0 0.12-0.25-0.5-1 $\mathrm{mg} \mathrm{L}^{-1}$ by evaluating and comparing the $\mathrm{EC}_{50}$. Vials were then placed into $50 \mathrm{~mL}$ conical centrifuge tubes ( 5 vials/tube), fixed on a rotatory wheel (speed $2 \mathrm{rpm}$ ) and kept at $20^{\circ} \mathrm{C}$. No surfactant was added. After $48 \mathrm{~h}$, nauplii were transferred from glass vials into a 
multiwell plate, to allow their observation with a stereomicroscope. The percentage of immobile organisms was evaluated, considering as immobile organisms that were unable to move any appendage in a period of up to $20 \mathrm{~s}$ of observation and light stimulation of well solution. Each treatment, including the control, was prepared in triplicates.

As reported in the previous paragraph, MP accumulation was also evaluated in copepods after $48 \mathrm{~h}$ by exposing nauplii to 1-4 $\mu \mathrm{m}$ Cospheric polyethylene green fluorescently labelled particles.

\subsubsection{Acartia clausi}

Acute lethal toxicity tests with A. clausi were conducted following standard methods [34] adapted to nauplius larvae. Biological quality of the stock was checked using 3,5-DCP as reference toxicant. The $48-\mathrm{h} \mathrm{LC}_{50}$ cannot depart from the range of 0.5 to $1.5 \mathrm{mg} \mathrm{L}^{-1}$ [34]. Additional acceptability criterion was percentage mortality of controls $\leq 10 \%$. From 48 to $72 \mathrm{~h}$ before the start of the test, $A$. clausi mature adults obtained from a laboratory stock maintained by ECIMAT (University of Vigo) were maintained in $2 \mathrm{~L}$ jars and fed with cell suspension of Rhodomonas lens in an isothermal room at $20^{\circ} \mathrm{C}$ with bubbling filtered air. Using a $40 \mu \mathrm{m}$ mesh, $\leq 24 \mathrm{~h}$ nauplii were collected and placed in a $250 \mathrm{~mL}$ beaker. Under binocular stereoscope 10 nauplii were delivered by glass pipette in each of the $20 \mathrm{~mL}$ glass vials with no air space. A total of 5 vials per treatment were used. Treatments included control FSW and serial dilutions of PE-MP and BP3-PE-MP (see Tables 1 and 2). The vials were placed in a rotatory wheel set at $1 \mathrm{rpm}$ at a temperature of $20 \pm 1{ }^{\circ} \mathrm{C}$ and under an $18 / 6 \mathrm{~h}$ light/dark photoperiod. No surfactant was added. Copepod survival was recorded after $48 \mathrm{~h}$ of exposure.

\subsubsection{Mytilus galloprovincialis}

Mature mussels were purchased in local markets and gametes were obtained by thermal induction of spawning, according to the methods described by Beiras and Bellas [36]. Mature 
oocytes were transferred to $50 \mathrm{~mL}$ measuring cylinders, ca. $100 \mu \mathrm{L}$ of diluted sperm were added, and the mixture was shaken gently to facilitate fertilization. Fertilized eggs were transferred before the first cleavage into $25 \mathrm{~mL}$ glass vials filled with no head space, at a density of 40 per $\mathrm{mL}$. The vials were filled to the top to avoid the presence of bubbles and placed in a rotatory wheel set at $9 \mathrm{rpm}$, except for the preliminary test (see below), at a temperature of $20 \pm 1{ }^{\circ} \mathrm{C}$ in the dark. After $48 \mathrm{~h}$ incubation, vials were fixed with two drops of $40 \%$ formalin and percentage of normal larvae ( $n=100$ per vial) was recorded under an inverted microscope (Carl Zeiss, Axiovert $40 \mathrm{CFL}$ ). Mussel larvae were considered abnormal when they did not reach veliger stage, showed irregular shape, convex hinge, and/or protruding mantle [37]. Control normality was always $>75 \%$.

A preliminary experiment was conducted to determine the most appropriate stirring method to evaluate the toxicity of microplastics to mussel embryos. With that aim, three PE concentrations: 20,50 and $100 \mathrm{mg} \mathrm{L}^{-1}$ plus a plastic free control $(n=4)$, were tested in static conditions, on a rotatory wheel $(9 \mathrm{rpm})$, and on an orbital shaker (200 rpm). Volume of experimental vials was $10 \mathrm{~mL}$ in static treatment and orbital shaker, and the remaining conditions were the same as described above. No surfactant was added. This experiment showed that the orbital shaker conditions significantly affected the development of larvae mussel, measured as the number of the total larvae and as the percentage of D-veliger larvae, in all concentrations tested of the microplastics. Subsequent experiments were conducted following above described methods except using rotatory mixing only. Control seawater and serial dilutions of PE-MP and BP3-PE-MP (see Tables 1 and 2) were tested.

\subsubsection{Paracentrotus lividus}

Adult sea-urchins were collected from the outer part of Ría de Vigo (NW Iberian Peninsula), maintained in $250 \mathrm{~L}$ glass fiber tanks with circulating sand-filtered seawater at a rate of $9 \mathrm{~L} \mathrm{~min}{ }^{-}$ ${ }^{1}$, and fed two times per week with natural collected algae. Temperature was $18 \pm 2 \stackrel{\circ}{ }$, salinity 
$34 \pm 2$ psu and oxygen $>5 \mathrm{mg} \mathrm{L}^{-1}$. Biological quality of the stock was checked using a certified $\left(1000 \pm 4 \mathrm{mg} \mathrm{L}^{-1}\right) \mathrm{Cu}$ standard solution. The $\mathrm{Cu} \mathrm{EC}_{50}$ values obtained cannot depart more than $30 \%$ from the historical chart data. According to the methods described by Beiras, Durán, Bellas and Sánchez-Marín [38], sea-urchin gametes were obtained by dissection of ripe adults, mature oocytes were transferred to $50 \mathrm{~mL}$ measuring cylinders, ca. $1 \mu \mathrm{L}$ of undiluted sperm were added, and the mixture was shaken gently to facilitate fertilization. Fertilized eggs were transferred before the first cleavage into $25 \mathrm{~mL}$ glass vials filled with no head space, at a density of 40 per $\mathrm{mL}$. The vials were placed in a rotatory wheel set at $1 \mathrm{rpm}$ at a temperature of $20 \pm 1{ }^{\circ} \mathrm{C}$ in the dark. Serial dilutions of PE-MP and BP3-PE-MP plus FSW and (when needed) solvent or dispersant controls were carried out. Four replicates per treatment were tested. In non-spiked MP experiments dispersion of the particles was facilitated by using $0.03 \mu \mathrm{L}$ of Tween ${ }^{\circledR} 20$ per mg MP. This yields a maximum Tween ${ }^{\circledR} 20$ concentration of $3 \mu \mathrm{L} \mathrm{L}^{-1}$, below the experimental NOEC of $7 \mu \mathrm{L} \mathrm{L}^{-1}$ obtained for this chemical in preliminary trials.

After $48 \mathrm{~h}$ incubation, vials were fixed with four drops of $40 \%$ formalin and length (maximum linear dimension in $n=35$ per vial) was recorded using an inverted microscope (Leica DMI 4000B) and Leica QWIN image analysis software. Acceptability criteria were percentage of fertilized eggs $>98 \%$ and size increase in controls $>253 \mu \mathrm{m}$ [39].

\subsubsection{Oryzias melastigma}

O. melastigma adults were reared at IFREMER from a stock obtained as embryos in 2007 from Doris Au's laboratory (State Key Laboratory in Marine Pollution, City University of Hong Kong, China). Juveniles and adult fish were reared in recirculating systems in water at 25 psu salinity in an isothermal room at $27 \pm 1{ }^{\circ} \mathrm{C}$ with a $14 / 10 \mathrm{~h}$ light/dark photoperiod. Eggs were collected by siphoning tanks bottom within hours after light onset and quickly cleaned. Then eggs were rolled on sandpaper (p.2000) as described for Japanese medaka [40], extensively rinsed in 
order to remove debris and finally transferred in Petri dish filled with artificial $20 \mu \mathrm{m}$-filtered synthetic artificial seawater (ASW) (Instant Ocean; salinity $25 \%$, $\mathrm{pH}=8$ ) containing methylene blue. Embryo-larval exposures have then been conducted within EPOC laboratory facility (University of Bordeaux). One day post fertilization (dpf) embryos, at morula stage, were exposed to virgin PE-MP at 1 and $10 \mathrm{mg} \mathrm{L}^{-1}$ until $13 \mathrm{dpf}$, at the end of eleutheroembryo phase. Control condition consisted in embryos reared in sea water only. Exposure units were $70 \mathrm{~mm}$ diameter glass Petri dishes, $25 \mathrm{~mL}$ of ASW and 30 embryos. Each treatment condition was replicated at least 3 times. The experiment took place in temperature-controlled chambers (Snidjers Scientific, Tilburg, The Nederlands) at $28 \pm 0.3^{\circ} \mathrm{C}$ with a $14: 10$ light:dark photoperiod, $5000 \mathrm{~lx}$ white light, under $27 \mathrm{rpm}$. rotation (horizontal shaker) to imitate low ocean hydrodynamics and synchronize hatching [41]. Half of the exposure medium was renewed daily. After hatching, yolk-sac larvae were transferred in glass beakers containing $20 \mathrm{~mL}$ of exposure medium. Yolk-sac larvae were not fed during the experiment. No surfactant was added. Dissolved oxygen was daily checked to be $>90 \%$ saturation using a fiber-optic oxygen mini-sensor Fibox 3 (PreSens Precision Sensor, Regensburg, Germany). Dead embryos and larvae were daily recorded and immediately removed to avoid alteration of the medium. Acute toxicity has been monitored using a stereomicroscope according to endpoints defined in OECD guideline TG236.

This study was conducted in accordance with the French and European policies on animal testing [43].

\subsection{Statistical methods}

Statistical analyses were conducted using IBM SPSS statistics software. Normal distribution and homoscedasticity of the data was checked using the Shapiro-Wilk's and Levene's tests respectively. When significant differences $(p<0.05)$ among groups were found using ANOVA then each treatment was compared to the control using Dunnett's post hoc test to calculate 
the no observed effect concentration (NOEC) and the lowest observed effect concentration (LOEC). Non-parametric post hoc tests were used for heteroscedastic data. Lethal (LC $\left.C_{50}\right)$ and Effective median concentrations $\left(\mathrm{EC}_{50}\right)$, i.e. concentrations causing a $50 \%$ reduction in survival or the sublethal endpoint recorded, and their $95 \%$ confidence limits, were calculated using Probit or Trimmed Spearman Karber analysis [44].

\section{Results}

\subsection{MP ingestion}

The rotifers, copepod nauplii, bivalve veliger, and the sea-urchin plutei larvae all actively ingested the MP offered at 1 and $10 \mathrm{mg} \mathrm{L}^{-1}$ (Fig. 1b-d), except for Rotogal PE that even after sieving seemed too large to be ingested by the biological models used. In rotifers and T. fulvus nauplii MP were also offered at $0.1 \mathrm{mg} \mathrm{L}^{-1}$. In those treatments ingested MP were not observed in T. fulvus, and only a small percentage $(<30 \%)$ of rotifers showed ingestion. Some differences in the distribution of ingested MP in the digestive system across taxonomic groups were noticed. MP preferentially accumulated at the end of the gut in copepod larvae (Fig. 1b), throughout the whole digestive tract in bivalve veliger and rotifers (Fig. 1a and c), and in the stomach in plutei larvae (Fig.1 d).

In the fish tests used in this study, embryos and larvae feed on their vitellus reserves during the time window tested (from 0 to $13 \mathrm{dpf}$ ). Microscope observations support the lack of internalization, but show direct contact of PE-MP onto embryos (Fig. 2). Particles stuck to the

villi (short non-attaching filaments) at the surface of the chorion. 


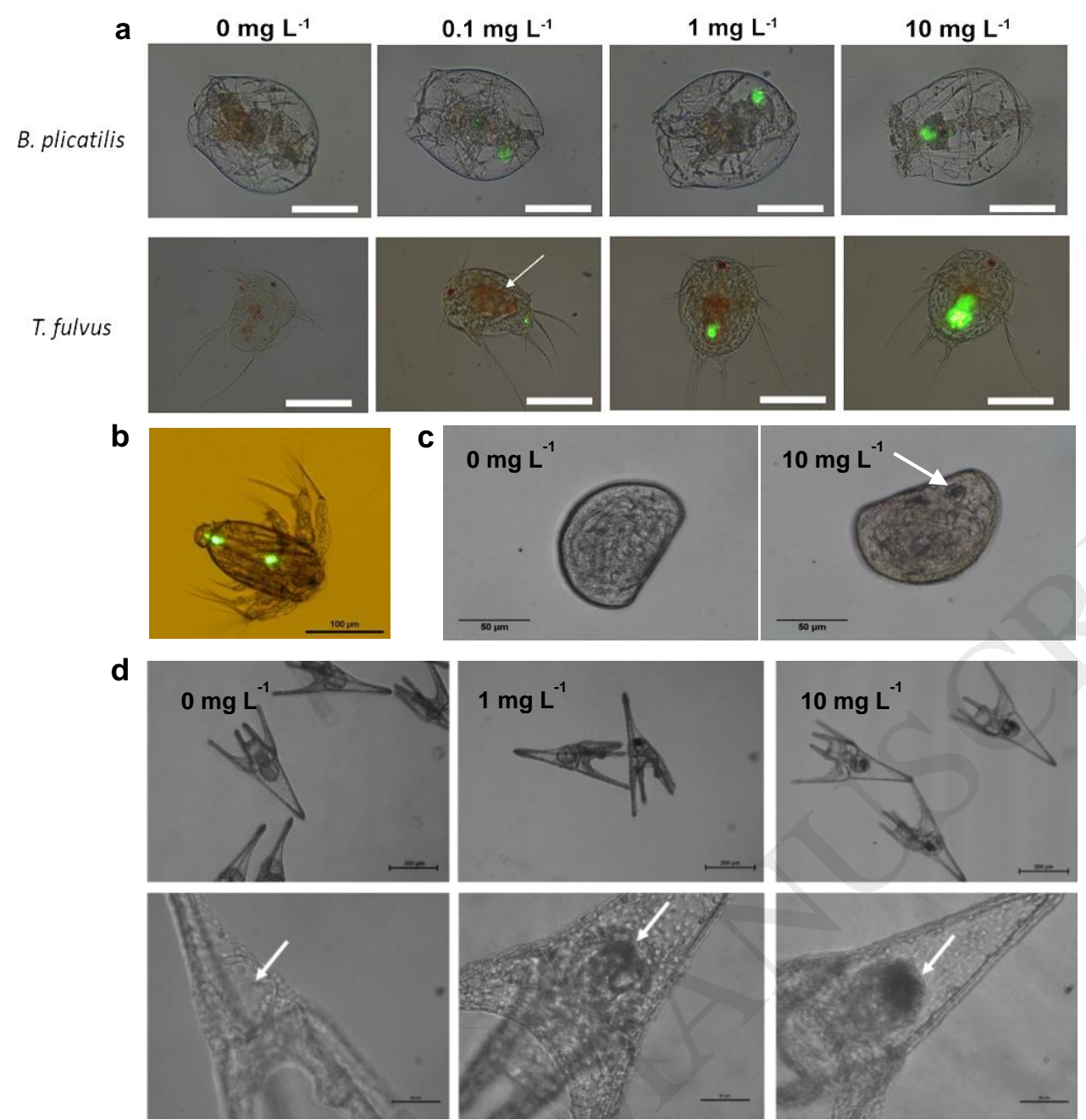

Fig. 1 Ingestion of microplastics. a, B. plicatilis and T. fulvus nauplii revealing fluorescent polyethylene microparticles (PE-MP) inside. Note that copepods did not ingest PE-MP at 0.1 $\mathrm{mg} \mathrm{L}^{-1}$ (arrow). Scale bars are $100 \mu \mathrm{m}$. b, A. clausi nauplius larvae with fluorescent PE-MP accumulated on the gut. Scale bar $100 \mu \mathrm{m}$. c, M. edulis larvae revealing PE-MP inside. Scale bar $50 \mu \mathrm{m} \mathrm{d}, P$. lividus larvae, notice the transparent stomachs in $0 \mathrm{mg} \mathrm{L}^{-1}$ in contrast with the dark filled stomachs in the other treatments. Top images $\times 10$ magnification, scale bars $200 \mu \mathrm{m}$ and down images $\times 40$ magnification, scale bars are $50 \mu \mathrm{m}$. 

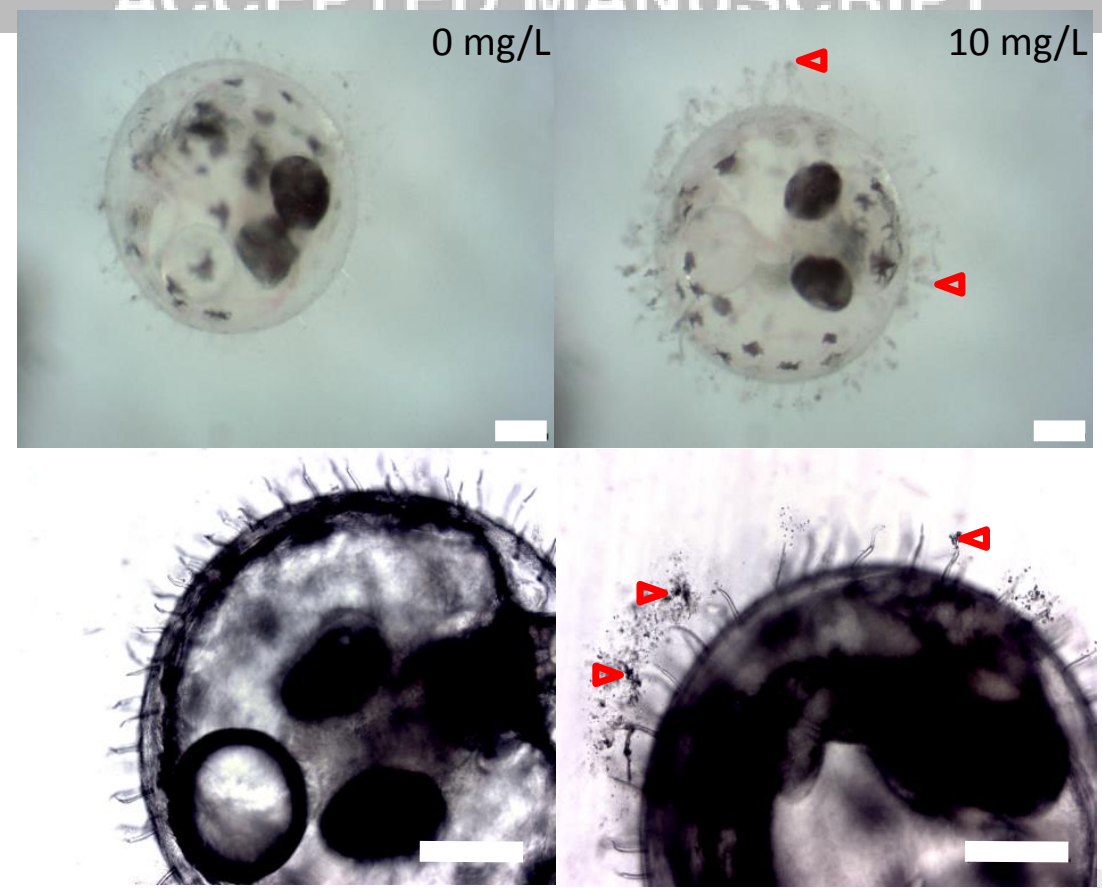

Fig. 2 Oryzias melastigma embryos exposed to 0 and $10 \mathrm{mg}$ PE-MP L $\mathrm{L}^{-1}(4-6 \mu \mathrm{m})$. Embryos are in direct contact with microplastics sticked on villi at the surface of the chorion. White scale bars $200 \mu \mathrm{m}$.

\subsection{Toxicity tests}

\subsection{1. 'Virgin' PE}

When tested in static conditions or in a rotatory wheel, there was no significant effect of any of the tested plastic materials on the mussel embryonic development, either measured as the total number of larvae or as the percentage of D-veliger larvae (Fig. 3). No interaction between MP concentration and mixing conditions was either observed in mussel larvae, according to results of a 2-way ANOVA. However, orbital shaking at the power needed to keep MP in suspension (200rpm) significantly reduced the number of normal D-veliger larvae at the end of the exposure period. Therefore, this kind of agitation causing abnormal development in the control was discarded for further testing. 


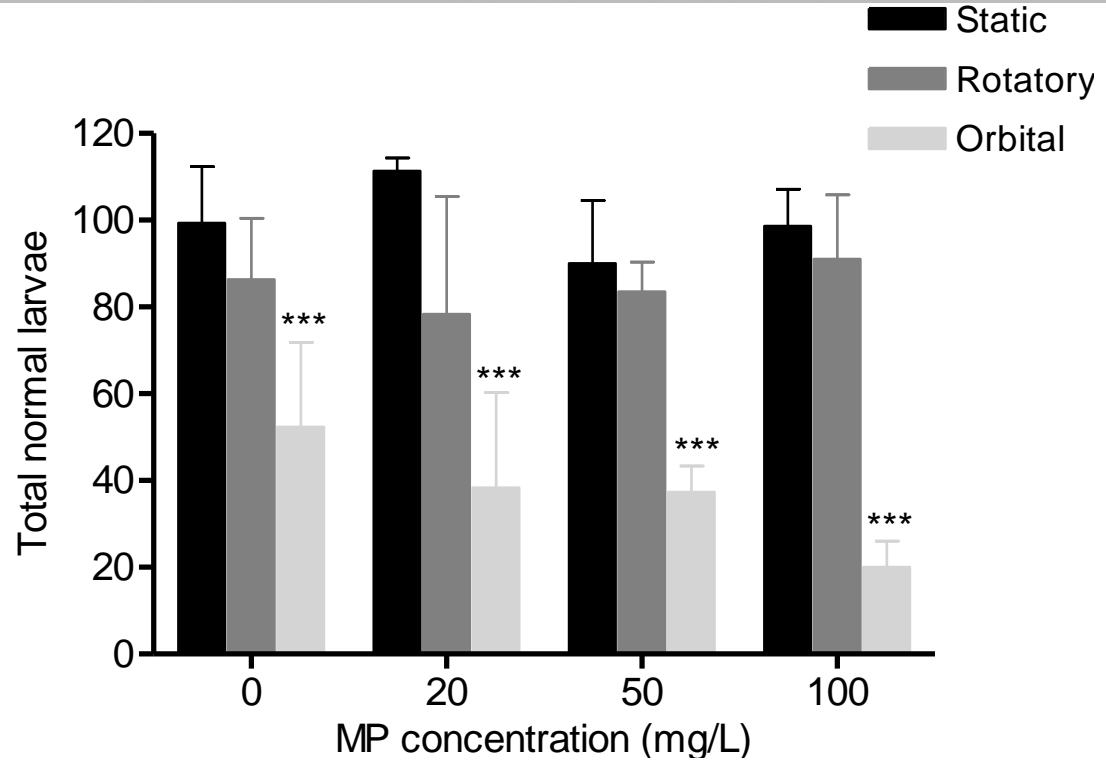

Fig 3. Mussel larval development after exposure of embryos to PE-MP (4-6 $\mu \mathrm{m})$ under static conditions, rotatory, and orbital shaking. Results are expressed as total normal larvae observed after $48 \mathrm{~h}$. The same number of embryos was transferred into each experimental vial. Bars represent mean $\pm S D(n=4)$. Asterisks refer to significant differences with 'static' treatments. $* * * p<0.001$.

The non-spiked PE-MP did not cause any significant effect at any of the concentrations tested below $30 \mathrm{mg} \mathrm{L}^{-1}$ in any of the biological models (Table 1), with the exception of the 1-4 $\mu \mathrm{m}$ particles, which showed a LOEC $=0.01 \mathrm{mg} \mathrm{L}^{-1}$ for $B$. plicatilis immobility, a LOEC $=1 \mathrm{mg} \mathrm{L}^{-1}$ for $B$. plicatilis mortality $\left(\mathrm{LC}_{50}>10 \mathrm{mg} \mathrm{L}^{-1}\right)$, and a $\mathrm{LOEC}=1 \mathrm{mg} \mathrm{L}^{-1}$ for $T$. fulvus mortality $\left(\mathrm{LC}_{50}=1.82 \mathrm{mg}\right.$ $\left.\mathrm{L}^{-1} ; 95 \% \mathrm{Cl}: 1.34-2.48\right)$.

Table 1. Toxicity testing conditions and results obtained with non-spiked polyethylene microparticles (PE-MP). ${ }^{(1)}$ mortality ${ }^{(2)}$ immobility ${ }^{(3)}$ mortality and immobility.

\begin{tabular}{ccccc}
\hline Test spp & MP size & $\begin{array}{c}\text { MP loads tested } \mathbf{m g} \\
\left.\mathbf{L}^{-1}\right)\end{array}$ & $\begin{array}{c}\text { NOEC/LOEC } \\
\left(\mathbf{m g ~ L}^{-1}\right)\end{array}$ & Stirring method \\
\hline B. plicatilis & $1-4 \mu \mathrm{m}$ & $0,0.01,0.1,1,10$ & $\begin{array}{c}\text { LOEC }=1^{(1)} \\
\text { LOEC }=0.01^{(2)} \\
\text { LOEC }>10\end{array}$ & Horizontal shaker \\
& $4-6 \mu \mathrm{m}$ & $0,0.01,0.1,1,10$ & Horizontal shaker \\
\hline T. fulvus & $1-4 \mu \mathrm{m}$ & $0,0.01,0.1,1,10$ & LOEC $=1$ & Rotatory wheel \\
& $4-6 \mu \mathrm{m}$ & $0,0.01,0.1,1,10$ & LOEC $>10$ & Rotatory wheel \\
\hline A. clausi & $4-6 \mu \mathrm{m}$ & $0,1,3,10,30$ & LOEC $>30$ & Rotatory wheel \\
\hline M. gallop. & $1-4 \mu \mathrm{m}$ & $0,20,50,100$ & LOEC $>100$ & Rotatory wheel \\
& $4-6 \mu \mathrm{m}$ & $0,20,50,100$ & LOEC $>100$ & Rotatory wheel \\
& $6-8.5 \mu \mathrm{m}$ & $0,20,50,100$ & LOEC $>100$ & Rotatory wheel \\
& $11-13 \mu \mathrm{m}$ & $0,20,50,100$ & LOEC $>100$ & Rotatory wheel \\
& $<63 \mu \mathrm{m}$ & $0,20,50,100$ & ROEC $>100$ & Rotatory wheel \\
\hline P. lividus & $4-6 \mu \mathrm{m}$ & $0,1,3,10,30,100$ & NOEC $=30$ & Rotatory wheel \\
& & & LOEC $=100$ &
\end{tabular}




\begin{tabular}{ccccc} 
& $11-13 \mu \mathrm{m}$ & $0,1,3,10,30,100$ & LOEC $>100$ & Rotatory wheel \\
& $11-15 \mu \mathrm{m}$ & $0,1,3,10,30,100$ & NOEC $=30$ & Rotatory wheel \\
& & & & \\
& $<40 \mathrm{~m}$ & $0,1,3,10,30,100$ & LOEC $=100$ & RoEC $>100$ \\
\hline O. melastigma & $4-6 \mu \mathrm{m}$ & $0,1,10$ & LOEC $>10$ & Rotatory wheel \\
\hline
\end{tabular}

\subsection{2. $B P$-3 and BP-3-spiked PE}

Chemical analyses of BP-3 on the different MP particles (fig. 4) show that a 100 -fold increase in dissolved BP-3 concentration reflects in a similar increase in measured BP-3 sorbed to the particles, except for the 11-13 $\mu \mathrm{m}$ particles with the low BP-3 treatment, which yielded sorbed BP-3 concentrations below the limit of detection ( $L O D=0.05 \mathrm{ng} / \mathrm{g}$ ). The BP-3 concentration in the non-spiked MP was always $<$ LOD.

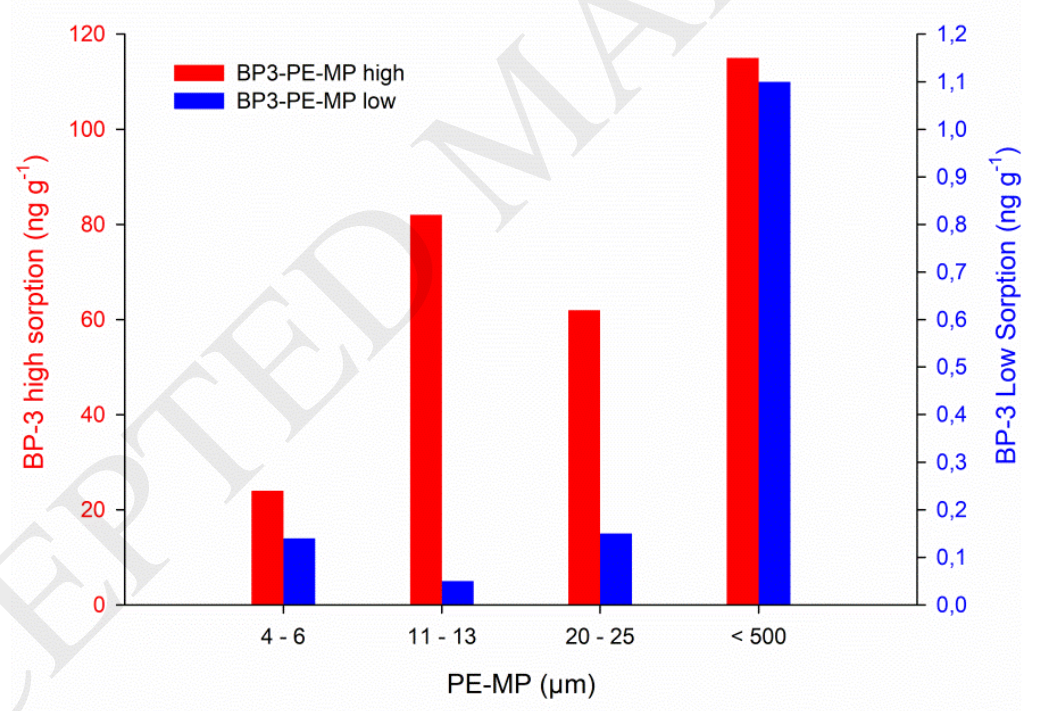

Fig. 4 BP-3 sorption on the different polyethylene microparticles (PE-MP) incubated at low and high BP-3 concentrations.

Table 2. Toxicity testing with BP-3-spiked polyethylene microparticles (BP3-PE-MP). The particles used for spiking where 4-6 $\mu \mathrm{m}$ PE-MP except when otherwise stated. Low and high concentrations of spiking correspond to incubations at 0.2 and $20 \mu \mathrm{g} \mathrm{L}-1$ BP-3 
respectively. For $B$. plicatilis, LOEC values refer to both immobility and mortality endpoints. 


\begin{tabular}{|c|c|c|c|c|}
\hline Test spp & Testing material & $\begin{array}{l}\text { Treatments tested } \\
\left(\mathrm{mg} \mathrm{L}^{-1}\right)\end{array}$ & $\begin{array}{c}\text { LOEC } \\
\left(\mathrm{mg} \mathrm{L}^{-1}\right)\end{array}$ & Stirring method \\
\hline \multirow[t]{2}{*}{ B. plicatilis } & Waterborne BP-3 & $0,0.5,1,2.5,5,10$ & LOEC $>10$ & Horizontal shaker \\
\hline & BP3-PE-MP high & $0,0.01,0.1,1,10$ & LOEC $>10$ & Horizontal Shaker \\
\hline T. fulvus & Waterborne BP-3 & $0,0.1,1,10$ & $\mathrm{LOEC}=1$ & Rotatory wheel \\
\hline \multirow[t]{3}{*}{ A. clausi } & Waterborne BP-3 & $0,0.01,0.05,0.25,0.5,1,2$ & $\mathrm{LOEC}=1$ & Rotatory wheel \\
\hline & BP3-PE-MP low & $0,1,10$ & LOEC $>10$ & Rotatory wheel \\
\hline & BP3-PE-MP high & $0,1,10$ & LOEC $>10$ & Rotatory wheel \\
\hline M. & BP3-PE-MP low & $0,1,10$ & LOEC $>10$ & Rotatory wheel \\
\hline galloprovincialis & BP3-PE-MP high & $0,1,10$ & LOEC $>10$ & Rotatory wheel \\
\hline \multirow{2}{*}{ P. lividus } & BP3-PE-MP low & $0,1,10$ & LOEC $>10$ & Rotatory wheel \\
\hline & BP3-PE-MP high & $0,1,10$ & LOEC $>10$ & Rotatory wheel \\
\hline \multirow[t]{4}{*}{ O. melastigma } & Waterborne BP-3 & $0,24 \times 10^{-9}, 24 \times 10^{-8}, 24 \times 10^{-6}$ & $\mathrm{LOEC}=0.24 \times 10^{-6}$ & Horizontal shaker \\
\hline & & $2.4 \times 10^{-3}, 0.024,0.24,2.4,24$ & & \\
\hline & BP3-PE-MP low & $0,1,10$ & $\mathrm{LOEC}=10$ & Horizontal shaker \\
\hline & BP3-PE-MP high & $0,1,10$ & $\mathrm{LOEC}=10$ & Horizontal shaker \\
\hline
\end{tabular}

Acute toxicity tests with waterborne BP-3 were conducted using B. plicatilis, T. fulvus, A. clausi, P. lividus and O. melastigma. $\mathrm{BP}-3 \mathrm{EC}_{50}$ values obtained were $1.8 \mathrm{mg} \mathrm{L}^{-1}(95 \% \mathrm{Cl}: 1.43-2.32)$ for T. fulvus, $1.3 \mathrm{mg} \mathrm{L}^{-1}$ for A. clausi, $4.11 \mathrm{mg} \mathrm{L}^{-1}(95 \% \mathrm{Cl}$ : $2.14-6.09)$ for $P$. lividus, and $>10 \mathrm{mg} \mathrm{L}^{-1}$ for B. plicatilis, far above those commonly found even in the most polluted waters. In the case of O. melastigma, LOEC was $0.24 \mathrm{ng} \mathrm{L}^{-1}$, and hatching rate was reduced to about a half at $24 \mathrm{ng} \mathrm{\textrm {L } ^ { - }}$

${ }^{1}$. However, the response was not monotonic and $\mathrm{EC}_{50}$ values were not calculable.

There were no significant effects of BP3-PE-MP at any of the spiking concentrations tested on any of the invertebrate planktonic organisms used (Table 2). In contrast, acute toxicity has been observed after 13-d exposure to MP-PE when spiked with BP-3 in fish embryos (Fig. 5). At low BP-3 concentration, $10 \mathrm{mg} \mathrm{L^{-1 }}$ BP3-PE-MP decreased embryonic survival and prevented hatching. At high BP-3 concentration, $10 \mathrm{mg} \mathrm{L}^{-1}$ did not significantly reduce embryonic survival but prevented hatching and induced premature hatching. 
PE-MP

BP3-PE-MP BP3-PE-MP

'low'

'high'
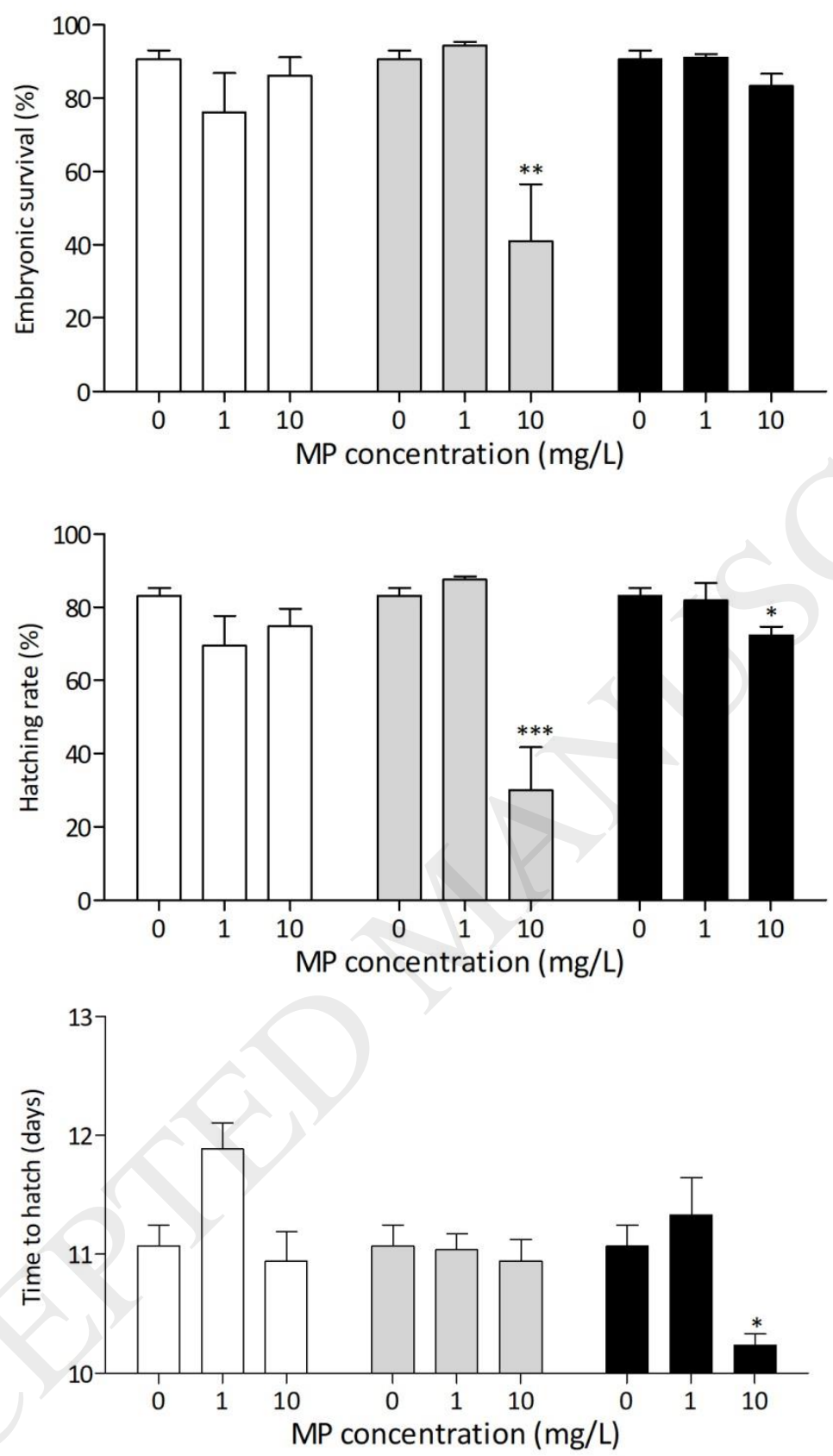

Fig 5. Toxicity of polyethylene microplastics to Oryzias melastigma embryos. Treatments included non-spiked polyethylene microplastics (PE-MP), and PE-MP spiked with BP-3 at 'low' and 'high' concentrations (BP3-PE-MP). Embryonic survival, hatching rate, and time to hatch was recorded after 12 days of exposure. Bars represent mean $\pm S D, N=3-6$. Asterisks refer to significant differences to the control treatment (C). ${ }^{*} p<0.05,{ }^{* *} p<0.01,{ }^{* * *} p<0.001$. 


\section{Discussion}

Oceans cover approximately 70 percent of the Earth's surface. Oceanic food webs are supported by plankton communities, important also for biodiversity as they host a wide variety of species and life forms. Plankton communities are composed not only by organisms such as rotifers and copepods that spend their whole life duration in the plankton (holoplankton), but also others such as bivalves and echinoderms that have planktonic larvae (meroplankton) although adult life stages inhabit the benthos. Furthermore, many pelagic fish lay their eggs in the neuston, the surface layer of the water, and larvae undergo a planktonic life. Therefore, potential effects of pollution on planktonic organisms will also affect the benthic and pelagic habitats.

ELS of copepods, bivalves, sea-urchins and fish are extremely sensitive to chemical pollutants, which explain their use in regulatory tools for the marine environment. Due to their low density, PE and other polymer MP accumulate in the surface layer of the water. Both weathering and biofouling may affect the buoyancy of these particles, which can be found also in the water column. Therefore, planktonic organisms are readily exposed to MP. In addition, planktonic suspension feeders such as rotifers, copepods, bivalve and echinoderm larvae are capable to ingest particles within the same size fractions that the MP used in this study, from 1 to $25 \mu \mathrm{m}$. Microplastic toxicity testing with water column organisms demands experimental set-up allowing homogeneous dispersion of the particles in the water column. We have found that smooth rotatory shaking allows MP dispersion and subsequent ingestion by zooplankton with no need of surfactants that may interfere in toxicity and depart from environmentally relevant conditions. For mussel larvae, rotatory shaking provided a homogeneous plastic suspension with both positive and negative buoyancy particles, and did not increase background mortality compared to static controls. In contrast orbital shaking caused unacceptably high background abnormalities in control treatments, probably due to physical 
damage caused at the high orbital speed (200rpm) needed to keep MP in suspension by this method of stirring. In the case of medaka eggs, a smooth shaking allowed both normal development of embryos and exposure (contact) of MPs to egg chorions.

Maximum densities on MP in marine surface waters range from 0.0002 and $0.32 \mathrm{mg} \mathrm{L}^{-1}$, with median of $0.0047 \mathrm{mg} \mathrm{L}^{-1}$ (reviewed [45]). We have tested toxicity at densities up to $100 \mathrm{mg} \mathrm{L}^{-1}$ and did not find any effects at concentrations up to $10 \mathrm{mg} \mathrm{L}^{-1}$ except for 1-4 $\mu \mathrm{m}$ particles for rotifers (LOEC $=0.01-1 \mathrm{mg} \mathrm{L}^{-1}$ ) and Tigriopus (LOEC $=1 \mathrm{mg} \mathrm{L}^{-1}$ ). Therefore the experimental evidence here provided does not support a significant effect of PE MP on a wide range of marine planktonic organisms at environmentally relevant conditions. This is in line with the several of the latest reports published testing effects of MP on marine zooplanktonic organisms [12-14].

When very high MP concentrations were tested we did find some effects on behavioral endpoints related to motility. Using different zooplankton species, Gambardella et al. [15] had already pointed out that behavioral responses were orders of magnitude more sensitive to MP than mortality. Other sublethal trait such as ingestion rate has also been reported to be affected by MP [11]. These findings support the use of behavioral endpoints as a suitable tool for detecting high MP contamination.

Microplastics have been hypothesized to play a role as vectors of hydrophobic organic compounds $(\mathrm{HOC})$ to marine organisms upon ingestion, since they accumulate $\mathrm{HOC}$ concentrations far above those in the water column [46] [47]. Other more recent studies question this role on the basis of simple equilibrium partitioning or more sophisticated thermodynamics models [48-51]. In order to tests the effects of MP as vectors of HOC to zooplankton, we used BP-3 as model organic, and intended to obtain MP spiked with two distinct concentrations of sorbed BP-3, termed 'high' and 'low'. To the best of our knowledge there are no data available on environmental concentrations of BP-3 in plastic or on toxicity of 
BP-3 sorbed to plastics. Therefore, the spiking protocol was designed using BP-3 concentrations in the water representative of toxic and environmentally relevant concentrations, respectively, according to the literature. The method was successful and, despite the comparatively short exposure time, the two distinctly different BP-3 concentrations were achieved, with final concentrations in the MPs ranging from 24 to $115 \mathrm{ng}$ $\mathrm{g}^{-1}$ for the high concentration, and from 0.14 to $1.1 \mathrm{ng} \mathrm{g}^{-1}$ for the low concentration, except for the low concentration with the 11-13 $\mu \mathrm{m}$ particles. However, the variation in BP-3 concentrations on the different MP size classes did not follow the expected pattern of a higher sorption rate in smaller (and thus with a higher surface to volume ratio) particles. This might be due to heterogeneity in size and shape within each class of commercial particles (see Supplementary Fig. 1). Although HOC sorption kinetics is a complex issue not addressed by the present experimental design and highly dependent on both inherent polymer properties and environmental weathering, we have found that the ingestion of MP spiked at BP-3 concentrations 100 times higher than those found in the most polluted coastal waters did not cause toxicity to the biological models tested, with the exception of fish ELS. This difference may be due to a higher sensitivity of these organisms and/or to the longer duration of the exposure. Similar approaches testing $\mathrm{HOC}$ with higher acute toxicity and $\mathrm{K}_{\mathrm{ow}}$ values are needed before these conclusions could be extended to other organic pollutants common in marine ecosystems.

\section{Conclusions}

All feeding stages of zooplanktonic organisms representative of marine taxa tested ingested PE-MP within the 1 to $10 \mu \mathrm{m}$ size range. Acute exposures of zooplanktonic marine invertebrates, including sensitive early life stages, to either virgin or BP-3 spiked polyethylene MP at densities above those reported in the most polluted marine waters did not cause any 
toxic effects. In contrast, fish ELS in contact with BP-3 spiked MP showed premature hatching and significantly decreased hatching rates compared to those in contact with virgin MP.

There is still a healthy debate in the scientific community as to whether MP pose an unacceptable risk to the receiving environment. The current study indicates that PE-MP do not pose a significant risk to marine zooplankton, and we recommend careful re-evaluation of the need to replace these polymers in consumer products, especially when little is known about the potential impacts of the alternatives.

\section{Acknowledgements}

The authors acknowledge D. Costas, C. Clérandeau, J.C. Crebassa and all the staff of ECIMAT, IFREMER and EPOC laboratories for their helpful technical support.

Funding: This research was conducted in the frame of the JPI-Oceans EPHEMARE Project, funded by the Spanish Government (MINECO) (PCIN-2015-187-C03-03 and CTM2016-77945C3); the French National Research Agency (Agence National de La Recherche) (ANR-15-JOCE0002-05); the Swedish Research Council for Environment, Agricultural Sciences and Spatial Planning (942-2015-1865). R.B. benefited from the Grant "Program of Consolidation and structuring of competitive research groups in the University system of Galicia" by the Galician Government (ED431C 2017/46). 


\section{References}

[1] J.R. Jambeck, R. Geyer, C. Wilcox, T.R. Siegler, M. Perryman, A. Andrady, R. Narayan, K.L. Law, Plastic waste inputs from land into the ocean, Science, 347 (2015) 768.

[2] K.L. Law, S.E. Morét-Ferguson, D.S. Goodwin, E.R. Zettler, E. DeForce, T. Kukulka, G. Proskurowski, Distribution of Surface Plastic Debris in the Eastern Pacific Ocean from an 11Year Data Set, Environ. Sci. Technol., 48 (2014) 4732-4738.

[3] F. Galgani, G. Hanke, T. Maes, Global Distribution, Composition and Abundance of Marine Litter, in: M. Bergmann, L. Gutow, M. Klages (Eds.) Marine Anthropogenic Litter, Cham,Springer International Publishing, 2015, pp. 29-56.

[4] D.K.A. Barnes, F. Galgani, R.C. Thompson, M. Barlaz, Accumulation and fragmentation of plastic debris in global environments. , Philosophical Transactions of the Royal Society, 364 (2009) 1985-1998.

[5] S. Beer, A. Garm, B. Huwer, J. Dierking, T.G. Nielsen, No increase in marine microplastic concentration over the last three decades - A case study from the Baltic Sea, Sci. Total Environ., 621 (2018) 1272-1279.

[6] M.W. Hart, Particle Captures and the Method of Suspension Feeding by Echinoderm Larvae, The Biological Bulletin, 180 (1991) 12-27.

[7] M. Cole, P. Lindeque, E. Fileman, C. Halsband, R. Goodhead, J. Moger, T.S. Galloway, Microplastic Ingestion by Zooplankton, Environ. Sci. Technol., 47 (2013) 6646-6655.

[8] O. Setälä, V. Fleming-Lehtinen, M. Lehtiniemi, Ingestion and transfer of microplastics in the planktonic food web, Environ. Pollut., 185 (2014) 77-83.

[9] C.R. Nobre, M.F.M. Santana, A. Maluf, F.S. Cortez, A. Cesar, C.D.S. Pereira, A. Turra, Assessment of microplastic toxicity to embryonic development of the sea urchin Lytechinus variegatus (Echinodermata: Echinoidea), Mar. Pollut. Bull., 92 (2015) 99-104.

[10] C. Martínez-Gómez, V.M. León, S. Calles, M. Gomáriz-Olcina, A.D. Vethaak, The adverse effects of virgin microplastics on the fertilization and larval development of sea urchins, Mar. Environ. Res., 130 (2017) 69-76.

[11] M. Cole, P. Lindeque, E. Fileman, C. Halsband, T.S. Galloway, The Impact of Polystyrene Microplastics on Feeding, Function and Fecundity in the Marine Copepod Calanus helgolandicus, Environ. Sci. Technol., 49 (2015) 1130-1137.

[12] K.L. Kaposi, B. Mos, B.P. Kelaher, S.A. Dworjanyn, Ingestion of Microplastic Has Limited Impact on a Marine Larva, Environ. Sci. Technol., 48 (2013) 1638-1645.

[13] M. Cole, T.S. Galloway, Ingestion of Nanoplastics and Microplastics by Pacific Oyster Larvae, Environ. Sci. Technol., 49 (2015) 14625-14632.

[14] R.J.E. Vroom, A.A. Koelmans, E. Besseling, C. Halsband, Aging of microplastics promotes their ingestion by marine zooplankton, Environ. Pollut., 231 (2017) 987-996. 
[15] C. Gambardella, S. Morgana, S. Ferrando, M. Bramini, V. Piazza, E. Costa, F. Garaventa, M. Faimali, Effects of polystyrene microbeads in marine planktonic crustaceans, Ecotoxicol. Environ. Saf., 145 (2017) 250-257.

[16] PlasticsEurope, Plastics - the Facts 2016. An analysis of European plastics production, demand and waste data. http://www.plasticseurope.org. Accessed 24/04/2018

[17] V. Hidalgo-Ruz, L. Gutow, R.C. Thompson, M. Thiel, Microplastics in the Marine Environment: A Review of the Methods Used for Identification and Quantification, Environ. Sci. Technol., 46 (2012) 3060-3075.

[18] K.H. Langford, K.V. Thomas, Inputs of chemicals from recreational activities into the Norwegian coastal zone, J. Environ. Monit., 10 (2008) 894-898.

[19] A. Sánchez Rodríguez, M. Rodrigo Sanz, J.R. Betancort Rodríguez, Occurrence of eight UV filters in beaches of Gran Canaria (Canary Islands). An approach to environmental risk assessment, Chemosphere, 131 (2015) 85-90.

[20] T. Tato, N. Salgueiro-González, V.M. León, S. González, R. Beiras, Ecotoxicological evaluation of the risk posed by bisphenol A, triclosan, and 4-nonylphenol in coastal waters using early life stages of marine organisms (Isochrysis galbana, Mytilus galloprovincialis, Paracentrotus lividus, and Acartia clausi). Environ. Pollut., 232 (2017) 173-182.

[21] E. His, R. Beiras, M.N.L. Seaman, The Assessment of Marine Pollution - Bioassays with Bivalve Embryos and Larvae. In:Advances in Marine Biology, (Academic Press, London ,1999). London.

[22] N. Kobayashi, Bioassay data for marine pollution using echinoderms, Encyclopedia of Environmental Control Technology, 9 (1995) 539-609.

[23] R. Beiras, Marine Pollution. Sources, fate and effects of pollutants in coastal ecosystems, $1^{\text {st }}$ ed. Elsevier, Amsterdam, 2018.

[24] A.L. Lusher, A. Burke, I. O'Connor, R. Officer, Microplastic pollution in the Northeast Atlantic Ocean: Validated and opportunistic sampling, Mar. Pollut. Bull., 88 (2014) 325-333.

[25] J.P.G.L. Frias, V. Otero, P. Sobral, Evidence of microplastics in samples of zooplankton from Portuguese coastal waters, Mar. Environ. Res., 95 (2014) 89-95.

[26] N. Blüthgen, S. Zucchi, K. Fent, Effects of the UV filter benzophenone-3 (oxybenzone) at low concentrations in zebrafish (Danio rerio), Toxicol. Appl. Pharmacol., 263 (2012) 184-194.

[27] K. Fent, P.Y. Kunz, A. Zenker, M. Rapp, A tentative environmental risk assessment of the UV-filters 3-(4-methylbenzylidene-camphor), 2-ethyl-hexyl-4-trimethoxycinnamate, benzophenone-3, benzophenone-4 and 3-benzylidene camphor, Mar. Environ. Res., 69 (2010) S4-S6.

[28] E. Paredes, S. Perez, R. Rodil, J.B. Quintana, R. Beiras, Ecotoxicological evaluation of four UV filters using marine organisms from different trophic levels Isochrysis galbana, Mytilus galloprovincialis, Paracentrotus lividus, and Siriella armata, Chemosphere, 104 (2014) 44-50.

[29] M. Schlumpf, B. Cotton, M. Conscience, V. Haller, B. Steinmann, W. Lichtensteiger, In vitro and in vivo estrogenicity of UV screens, Environ. Health Perspect., 109 (2001) 239-244. 
[30] ASTM, American Society for the Testing of Materials International standards. Standard guide for acute toxicity test with the rotifer Brachionus. E 1440-91. Annual book of ASTM, vol 11.05. West Conshohocken, PA, pp 830-837., 2004.

[31] F. Garaventa, C. Gambardella, A. Di Fino, M. Pittore, M. Faimali, Swimming speed alteration of Artemia sp. and Brachionus plicatilis as a sub-lethal behavioural end-point for ecotoxicological surveys, Ecotoxicology, 19 (2010) 512-519.

[32] F. Nasser, I. Lynch, Secreted protein eco-corona mediates uptake and impacts of polystyrene nanoparticles on Daphnia magna, Journal of Proteomics, 137 (2016) 45-51.

[33] UNICHIM, Associazione per l'univicazione nel settore dell 'industria chimica ente federato all 'uni UNICHIM 2396:2014 Qualitàdell'acqua - Determinazione della tossicità letale a 24h,48h e 96h di esposizione con nauplidi Tigriopus fulvus (Fischer,1860) (Crustacea:Copepoda). 2014.

[34] ISO14669, Water quality: Determination of acute lethal toxicity to marine copepods (Copepoda, Crustacea), Genève, Switzerland, 1999.

[35] O. Faraponova, E. Giacco, F. Biandolino, E. Prato, F. Del Prete, A. Valenti, S. Sarcina, A. Pasteris, A. Montecavalli, S. Comin, C. Cesca, M. Francese, M. Cigar, V. Piazza, F. Falleni, I. Lacchetti, Tigriopus fulvus: The interlaboratory comparison of the acute toxicity test, Ecotoxicol. Environ. Saf., 124 (2016) 309-314.

[36] R. Beiras, J. Bellas, Inhibition of embryo development of the Mytilus galloprovincialis marine mussel by organic pollutants; assessment of risk for its extensive culture in the Galician Rias., Aquaculture, 277 (2008) 208-212.

[37] E. His, M.N.L. Seaman, R. Beiras, A simplification the bivalve embryogenesis and larval development bioassay method for water quality assessment., Water Res., 31 (1997) 351-355.

[38] R. Beiras, I. Durán, J. Bellas, P. Sánchez-Marín, Biological effects of contaminants: Paracentrotus lividus sea urchin embryo test with marine sediment elutriates. ICES Techniques in Marine Environmental Sciences. Num 51, 13 pp., International Council for the Exploration of the Sea, Copenhagen, Denmark, 2012.

[39] L. Saco-Álvarez, I. Durán, J. Ignacio Lorenzo, R. Beiras, Methodological basis for the optimization of a marine sea-urchin embryo test (SET) for the ecological assessment of coastal water quality., Ecotoxicol. Environ. Saf., 73 (2010) 491-499.

[40] S.R. Porazinski, H. Wang, M. Furutani-Seiki, Dechorionation of Medaka Embryos and Cell Transplantation for the Generation of Chimeras, Journal of Visualized Experiments : JoVE, (2010) 2055.

[41] A. Farwell, V. Nero, M. Croft, P. Bal, D.G. Dixon, Modified Japanese Medaka Embryo-Larval Bioassay for Rapid Determination of Developmental Abnormalities, Arch. Environ. Contam. Toxicol., 51 (2006) 600-607.

[42] OECD Organization for Economic Cooperation and Development Guidelines for the testing of chemicals. Section 2: effects on biotic systems test no. 236: Fish embryo acute toxicity (FET) test, (Paris, OECD Publishing, 2013). 
[43] Directive 2010/63/EU of the european parliament and of the council of 22 September 2010 on the protection of animals used for scientific purposes, (Official Journal of the European Union, 2010).

[44] D.J. Finney, Statistical Method In Biological Assay, 3rd ed. ed., (London, Charles Griffin \& Co. Ltd, 1978).

[45] I.L. Nerland, C. Halsband, I. Allan, K.V. Thomas, REPORT SNO. 6754-2014. Microplastics in marine environments: Occurrence, distribution and effects, in, Akvaplan-niva, Oslo, 2014.

[46] A. Bakir, S.J. Rowland, R.C. Thompson, Enhanced desorption of persistent organic pollutants from microplastics under simulated physiological conditions, Environ. Pollut., 185 (2014) 16-23.

[47] C.G. Avio, S. Gorbi, M. Milan, M. Benedetti, D. Fattorini, G. d'Errico, M. Pauletto, L. Bargelloni, F. Regoli, Pollutants bioavailability and toxicological risk from microplastics to marine mussels, Environ. Pollut., 198 (2015) 211-222.

[48] A.A. Koelmans, A. Bakir, G.A. Burton, C.R. Janssen, Microplastic as a Vector for Chemicals in the Aquatic Environment: Critical Review and Model-Supported Reinterpretation of Empirical Studies, Environ. Sci. Technol., 50 (2016) 3315-3326.

[49] L.M. Ziccardi, A. Edgington, K. Hentz, K.J. Kulacki, S. Kane Driscoll, Microplastics as vectors for bioaccumulation of hydrophobic organic chemicals in the marine environment: A state-ofthe-science review, Environ. Toxicol. Chem., 35 (2016) 1667-1676.

[50] B. Beckingham, U. Ghosh, Differential bioavailability of polychlorinated biphenyls associated with environmental particles: Microplastic in comparison to wood, coal and biochar, Environ. Pollut., 220 (2017) 150-158.

[51] R. Lohmann, Microplastics are not important for the cycling and bioaccumulation of organic pollutants in the oceans-but should microplastics be considered POPs themselves?, Integr. Environ. Assess. Manage., 13 (2017) 460-465. 